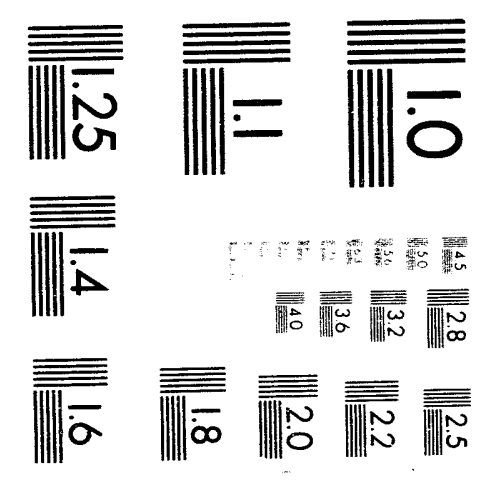



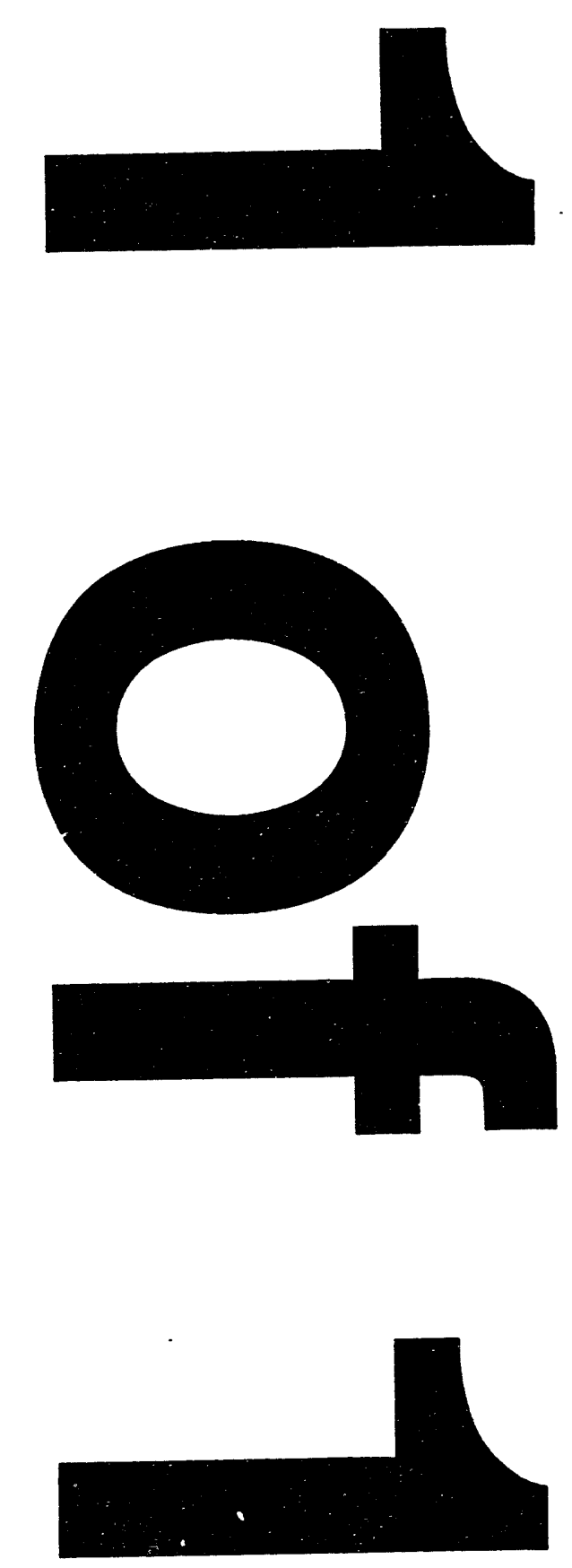


\title{
A PROCESS FOR DETERMINING RADIOHALOGENS
}

\author{
W. J. Washington \\ F. A. Hohorst
}

December 1993

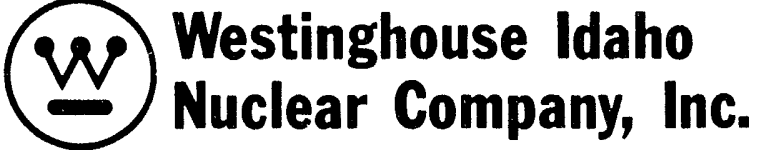

PREPARED FOR THE

DEPARTMENT OF ENERGY IDAHO OPERATIONS OFFICE

UNDER CONTRACT DE-AC07-84ID12435

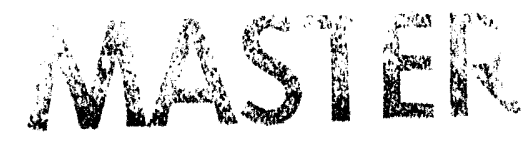




\title{
A PROCESS FOR DETERMINATION OF RADIOHALOGENS
}

\author{
W. J. Washington and F. A. Hohorst
}

\begin{abstract}
Techniques for the separation and potential determination of chlorine-36 and iodine-129 were examined. Separation was based upon addition to the carbon-carbon double bond in 1-hexene. These specific organic halides formed an acceptable liquid scintillation counting cocktail with chlorine but not with iodine. The miscibility of 1,2-dichlorohexane should allow a larger mass of sample in a scintillation cocktail, lowering the detection limit of the determination of chlorine-36. Organic halides are also expected to be more receptive to waste treatment than metals such as silver. These techniques offer the potential for determination of chlorine-36 in groundwater samples while producing less mixed waste than some current analytical techniques.
\end{abstract}

\section{INTRODUCTION}

Water quality is monitored at any of the many locations at the Idaho National Engineering Laboratory (INEL) in southeast Idaho. Chlorine-36 and iodine-129 are of special interest because they are readily assimilated into living tissue. Liquid scintillation counting (LSC) is one method for determination of radioactivity which is readily adapted to large sample throughput.

Some methods of halide determination precipitate halide ion from solution using silver nitrate,2. Silver is a heavy metal which is hazardous 
to the environment. The identification of an efficient alternative to silver is desirable.

Conversion of halides to halogens or hydrohalides followed by addition to carbon-carbon bonds provides one means by which halides may be isolated. Chlorine is prepared through a reaction with acidic permanganate. Hydroiodic acid is formed by action of a strong, non-oxidizing acid on iodide.

1-Hexene is an appropriate substrate because it has a useful difference between its boiling point and the high boiling points of 1,2-dichlorohexane and 2 -iodohexane ${ }^{3}$. The differences in boiling points and densities make the product easy to separate and distinguish from the reactant.

Once halogens have been incorporated into organic molecules and purified, they may be added to a liquid scintillation cocktail to count the beta particles given off by radioactive halogen atoms. The measured light intensity then provides a measure of the radioactivity of the sample $e^{4}$.

\section{EXPERIMENTAL}

\section{General}

All experimentation was performed inside a fume hood. All chemical reactions took place inside glass/Teflon ${ }^{\text {m }}$ systems assembled from wheaton semimicro kits. Nitrogen flow rate was measured by a Matheson mass flow meter Model 8111-0422 [0 - 200 normal cubic centimeters per minute (nccm, $\pm 3 \%$ of full scale)]. Samples were counted on a Beckman liquid scintillation system, Model 5801, in $20 \mathrm{~mL}$ low potassium glass vials.

\section{Reagents}

All chemicals used were of reagent grade, unless otherwise stated below: Hexene, Kodak stock \#15613 
Nitrogen gas was supplied to the building from a liquid nitrogen tank. Optifluor ${ }^{\circledR}$, Packard Instrument Co.

$95 \%$ Phosphoric acid, from prepared stock reagents ${ }^{5}$.

\section{Density}

Densities were determined at ambient temperatures ( 20 to $24^{\circ} \mathrm{C}$ ) using Fisher Brand 250, 500 or $1000 \lambda$ micropipettes which were calibrated "to contain" and had a stated accuracy of $\pm 0.2 \%$ at $20^{\circ} \mathrm{C}$. No temperature corrections were applied to the experimentally determined densities. The accuracy of densities determined using each size micropipette was no better than $\pm 0.008, \pm 0.005$, and $\pm 0.003 \mathrm{~g} \mathrm{~cm}^{-1}$, respectively

\section{Chloride}

Isolation of chloride via generation and reaction as chlorine took place in the apparatus shown schematically in Figure 1. Typically, chlorine was prepared by the oxidation of chloride with a potassium permanganate - sulfuric acid solution ${ }^{6,7}$. The reaction flask was attached to an addition funnel containing a known amount of chloride, and a reflux condenser. Nitrogen gas continuously bubbled through the mixture in a reaction flask at $100 \mathrm{cc} / \mathrm{min}$. A connection from the top of the reflux condenser lead to empty vial \#I. Sulfuric acid was used in vial \#2 to dry the chlorine gas. Chlorine gas bubbled through vials \#3 and \#4 reacting with the hexene $10.6731 \mathrm{~g} / \mathrm{cc}$ @ at $20^{\circ} \mathrm{C}^{3}$ ) to form 1,2-dichlorohexane. Vial \#4 was a backup intended to trap that which passed through vial \#3 without reacting. The system was purged with a 170 nccm nitrogen stream for 15 minutes, prior to heating for 7 hours. 1 -Hexene $(\approx 10 \mathrm{~mL}$ every $45 \mathrm{~min})$ was added to vial \#3 to replenish evaporated hexene, thereby maintaining ihe quantity present at 5 to $15 \mathrm{~mL}$; the second vial was replenished with hexene approximately every 2.5 hours in the same 
manner. After 7 hours, vials \#3 and \#4 were removed, capped, and stored overnight. A $100 \mathrm{cc} / \mathrm{min}$ nitrogen stream was passed through the vials ove: these hexene mixtures to purify the product. The mass of the product mitures was then monitored until the mass loss became low and constant. Constart mass loss signified that all of the hexene had evaporated and only the 1,2dichlorohexane product remained.

Iodide.

Isolation of iodide via generation and reaction as hydrogen iodide took place in the apparatus shown schematically in Figure 2. A typical iodide separation experiment was performed by adding hexene and potassium iodide to 958 orthophosphoric acid in a round bottom fiask ${ }^{89}$. A 15 minute nitrogen purge displaced air in the system. The flask was heated under reflux for 3 hours with constant stirring. The contents of the reaction flask were then washed into a separatory funnel with approximately $15 \mathrm{ml}$ diethyl ether. The funnel was shaken vigorously and the layers were allowed to separate. The potassium phcsphate/sodium iodide containing aqueous layer was drawn off. About $5 \mathrm{ml}$ of $9 \%$ sodium thiosulfate solution was added. The funnel was shaken, the layers allowed to separate, and the aqueous sodium thiosulfate/sodium dithionate withdrawn. The ether layer was washed with a saturated solution of sodium chloride and dried over anhydrous sodium sulfate. The product - ether mixture was then poured into an impinger vial and purged at 26 nccm nitrogen flow to evaporate the ether leaving the purified product. The impinger was covered in aluminum foil and a strip of copper placed in the impinger to minimize decomposition during this evaporation step. 


\section{RESULTS}

\section{Chloride}

In these experiments, the theoretical reaction which takes place in the

flask is:

$6 \mathrm{Cl}^{-}+2 \mathrm{KMnO}_{4}+4 \mathrm{H}_{2} \mathrm{SO}_{4} \rightarrow 2 \mathrm{MnO}_{2}+3 \mathrm{SO}_{4}{ }^{2-}+\mathrm{K}_{2} \mathrm{SO}_{4}+3 \mathrm{Cl}_{2}$ (gas) $+4 \mathrm{H}_{2} \mathrm{O}$

The $\mathrm{MnO}_{2}, \mathrm{~K}^{+}, \mathrm{SO}_{4}^{2-}$ and most of the water remain in the flask. Water vapor is absorbed by concentrated $\mathrm{H}_{2} \mathrm{SO}_{4}$ in the first impinger in the train. Chlorine gas passed into the hexene where it reacted according to the equation:

$$
\mathrm{Cl}_{2}+\mathrm{C}_{6} \mathrm{H}_{12} \rightarrow \mathrm{C}_{6} \mathrm{H}_{12} \mathrm{Cl}_{2}
$$

About $97 \%$ of the $\mathrm{C}_{6} \mathrm{H}_{12} \mathrm{Cl}_{2}$ formed was in vial \#3. A complete listing of these results are presented in Table 1.

Table 1 .

Chloride separation Reactions.

\begin{tabular}{|c|c|c|c|c|c|c|c|}
\hline \multirow[t]{2}{*}{ Run } & \multirow{2}{*}{$\begin{array}{r}\text { Time } \\
(\mathrm{h})\end{array}$} & \multicolumn{4}{|c|}{ Quantities (mmol) } & \multirow{2}{*}{$\begin{array}{l}\text { Density } \\
(g / C C)\end{array}$} & \multirow{2}{*}{$(\&)^{\text {Yielo }}$} \\
\hline & & Halide & $\mathrm{KMnO}_{4}$ & $\mathrm{H}_{2} \mathrm{SO}_{4}$ & $\mathrm{C}_{6} \mathrm{H}_{12} \mathrm{Cl}_{2}$ & & \\
\hline \#1 & 7.00 & 52.13 & $2 \% .84$ & 187.7 & 21.53 & 1.056 & 82.5 \\
\hline$\# 2$ & 7.75 & 30.06 & 27.89 & 170.6 & 15.03 & 1.048 & 55.4 \\
\hline \#3 & 4.00 & 55.27 & 28.52 & 187.7 & 23.68 & 1.052 & 76.7 \\
\hline
\end{tabular}

Run \#1 used sodium chloride whereas Run \#2 used potassium chloride. Run \#3 used a solid sample of bulk, commercial sodium chloride placed directly in the reaction flask; acidic permanganate solution was added in small batches over the course of $2.67 \mathrm{~h}$. The product was purified in each case by passing a nitrogen stream over the 1-hexene / 1,2-dichlorohexane mixture. The 1-hexene evaporated readily leaving the purified product. The reported density of $1,2-$ dichlorohexane is $1.085 \mathrm{~g} / \mathrm{CC}$ at $15^{\circ} \mathrm{C}^{2}$. Yields were $82.5 \%, 55.48$, and $76.7 \%$, respectively. 
Iodide

The net theoretical reaction which took place in the reaction flask is:

$$
\mathrm{C}_{6} \mathrm{H}_{12}+\mathrm{KI}+\mathrm{H}_{3} \mathrm{PO}_{4} \rightarrow \mathrm{C}_{6} \mathrm{H}_{13} \mathrm{I}+\mathrm{KH}_{2} \mathrm{PO}_{4}
$$

A completed list of the results is reported in Table 2 .

Table 2 .

\begin{tabular}{|c|c|c|c|c|c|c|c|c|}
\hline \multirow[t]{2}{*}{ Run } & \multirow{2}{*}{$\begin{array}{r}\text { Time } \\
\text { (h) }\end{array}$} & \multicolumn{5}{|c|}{ Quantities (mmol) } & \multirow{2}{*}{$\begin{array}{l}\text { Density } \\
(\mathrm{g} / \mathrm{cc})\end{array}$} & \multirow{2}{*}{$\left(\frac{\gamma}{\partial}\right)^{\text {Yield }}$} \\
\hline & & $\mathrm{C}_{6} \mathrm{H}_{12}$ & $\mathrm{KI}$ & $\mathrm{H}_{3} \mathrm{PO}_{4} \quad \mathrm{H}$ & & & & \\
\hline 1 & 3 & 88.52 & 28.92 & 271.28 & 36.91. & 4.32 & 1.424 & 14.9 \\
\hline 2 & 3 & 87.93 & 28.24 & 82.34 & 23.59 & 3.52 & 1.420 & 12.5 \\
\hline 3 & 3 & 137.74 & 30.91 & 316.77 & 90.77 & 22.54 & 1.418 & 72.9 \\
\hline 4 & 3 & 95.41 & 30.01 & 262.89 & 75.33 & 22.51 & 1.428 & 74.7 \\
\hline 5 & 3 & 91.73 & 43.71 & 179.92 & 51.56 & 21.34 & 1.422 & 48.8 \\
\hline
\end{tabular}

There were differences among the iodide runs relating to the flow rate and to where the flow of nitrogen entered the system. The conditions of Run \#2 were approximately the same as those in Run \#1 which was described as typical. In Run \#3, after purging for 15 minutes at $114 \mathrm{nccm}$ the nitrogen gas line was removed and that port capped. In Run \#4 the system was purged then capped for 1.5 hours, after which the nitrogen was admitted through inlet \#2 for 1.5 hours. In Run \#5 the system was purged through inlet \#1 at 200 nccm. The nitrogen flow was redirected to inlet \#2 for the remainder of the experiment at about $33 \mathrm{nccm}$. The observed densities were close to the reported density of $1.4354 \mathrm{~g} / \mathrm{CC}$ at $17^{\circ} \mathrm{C}^{2}$. The experimental runs produced varying yields of 2 -iodohexane as shown in Table 2 . 


\section{Liquid Scintillation Counting}

The prospects for implementation of this method rely on incorporation of the isolated product containing a radiohalogen (or a pseudoradiohalogen) into a liquid scintillation cocktail. To study these prospects, Optifluor 0 , a cocktail formulated for organic liquids, was used. The manufactuxer's literature stated that this cocktail was compatible with solvents such as dichloromethane, chloroform, and tetrachloromethane.

A set of five samples were prepared in glass LsC vials. Each was filled with $8.642 \pm 0.006$ grams $(\approx 10 \mathrm{~mL})$ of Optifluor ${ }^{\oplus} 0.1,2$-Dichlorohexane $(5.0$ mmol, $\approx 0.5 \mathrm{M})$ was added to one vial; subsequent additions of it to that same vial doubled the quantity added. The prepared 2 -iodohexane was similarly added to another vial beginning with $5.0 \mathrm{mmol}(\approx 0.5 \mathrm{M}$ ) except that a $27 \mathrm{mg}$ sliver of copper sheet was also added to that vial. The halogen containing species were all completely miscible forming a single liquid phase.

The count rates for a typical blank vial containing optifluor ${ }^{(1}$ and for blanks containing added 1 -hexene are reported in Table 3 . Quenching for these vials averaged 52-66 channels and were within the normal operating envelop of the instrument.

The count rates for the 1,2-dichlorohexane containing cocktail are recorded in Table 4 for a range of 5.0 to $40.0 \mathrm{mmol}$. All solutions were colorless except the highest concentration which was faintly yellow. Fluorescence is postulated to become significant at high concentrations as shown by the data in Tables 4 and 5 . This fluorescence decays with a halflife of about 5 hours. 
Table 3

Liquid Scintillation Counting Rates for optifluor ${ }^{\oplus} \circ$ Blank and for Optifluor ${ }^{\oplus} \circ / 1$-Hexene Mixtures ${ }^{\mathrm{a}}$

\begin{tabular}{ccccc} 
Vial & \multicolumn{1}{c}{$\begin{array}{c}\text { Count Rate } \\
(\mathrm{cpm})\end{array}$} & & $\begin{array}{c}\text { Count Rate } \\
(\mathrm{cpm})\end{array}$ & $\begin{array}{c}\text { Quenching } \\
\text { (channels) }\end{array}$ \\
${$\cline { 3 - 3 }$} } }$ & $34.02,34.35,35.28$ & & $19.90,20.72,21.40$ & $53,52,54$ \\
$\# 3^{\mathrm{f}}$ & $34.00,34.75,35.35$ & $21.18,21.82,21.47$ & $63,61,61$ \\
$\# 5^{8}$ & $37.33,36.47,37.07$ & $22.47,22.77,22.52$ & $65,66,66$
\end{tabular}

a Count rates are expressed as counts per minute for a $1 \mathrm{~h}$ count; recounts were made after 4-5 h.

b Count rate for channels 400 to 860 ( $\approx 20$ to $710 \mathrm{keV}$ )

c Count rate for channels 400 to 670 ( $\approx 20$ to $150 \mathrm{keV})$

d Expressed as the number of channels decreased.

e Typical data for $10 \mathrm{~mL}$ of Optifluor ${ }^{\circledR} 0$.

$f 10 \mathrm{~mL}$ of Optifluor ${ }^{\oplus} \mathrm{O}$ plus $5.1 \mathrm{mmol} 1$-hexene.

B $10 \mathrm{~mL}$ of Optifluor ${ }^{\oplus}$ O plus $10.0 \mathrm{mmol} 1$-hexene. 
Table 4

Liquid Scintillation Counting Rates for 1,2-Dichlorohexane -- Optifluor ${ }^{\circledR}$

1, 2-Dichlorohexane Added (mmol)

Count Rate
$(\mathrm{cpm})$

Count Rate ${ }^{c}$
$(\mathrm{cpm})$

Quenching ${ }^{\mathrm{d}}$

$\bullet$

5.0

$40.77,39.42,41.05$

$26.53,26.20,26.48$

$134,137,140$

10.0

$46.27,46.12,44.82$

$31.77,30.07,29.03$

$176,179,183$

20.0

$148.0,60.05,53.78$

$3.28 .8,40.47,35.48$

$242,244,245$

40.0

$1869,1544,501.0$

$1846,1520,478.2$

$323,325,326$

a count rates are expressed as counts per minute for a $1 \mathrm{~h}$ count or for a $2 \sigma$ counting uncertainty of $2 \frac{\%}{\text {; }}$ recounts were made after $3-5 \mathrm{~h}$.

b Count rate for channels 400 to 860 ( $\approx 20$ to $710 \mathrm{keV})$

c Count rate for channels 400 to 670 ( $\approx 20$ to $150 \mathrm{keV}$ )

d Expressed as the number of channels decreased. 
Table 5

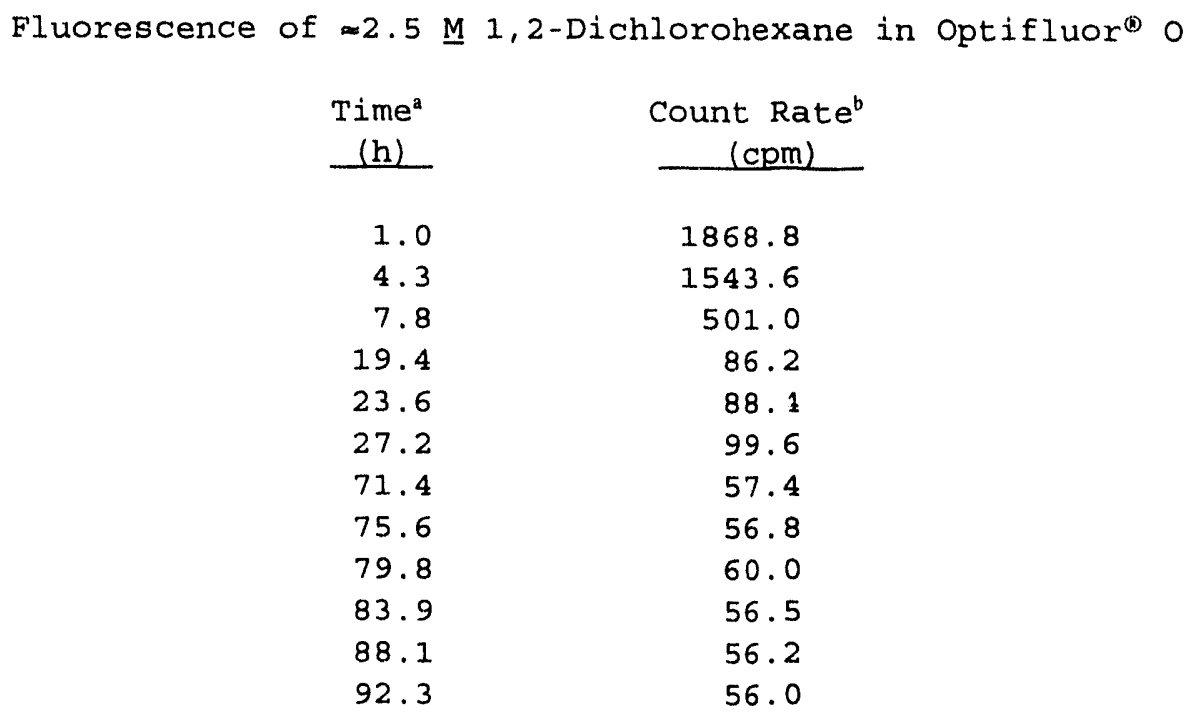

a Time since addition of last aliquot of 1,2-dichlorohexane to beginning of counting.

b Count rate for channels 400 to 860 ( $\approx 20$ to $710 \mathrm{keV}$ ) 
The count rates for the 2 -iodohexane containing cocktail are recorded in Table 6. Subsequent doubling of the 2 -iodohexane resulted in a solution that the instrument rejected because of excessive quenching. Consequently, no further counting data regarding this compound was collected.

Table 6

Liquid Scintillation Counting Rates for 2-Iodohexane - Optifluor $0^{\circledR}$

2-Iodohexane

Added

(mmol)

5.0

10.2

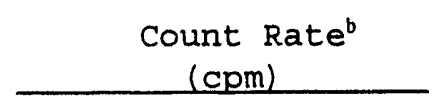

$41.78,41.15,40.68$

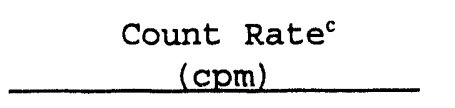

$18.78,19.18,19.23$
Quenching ${ }^{d}$

(channels)

$464,466,461$

a Count rates are expressed as counts per minute for a $1 \mathrm{~h}$ count or for a $2 \sigma$ counting uncertainty of $2 \%$; recounts were made after $4-5 \mathrm{~h}$.

$b$ Count rate for channels 400 to 860 ( $\approx 20$ to $710 \mathrm{keV}$ )

c Count rate for channels 400 to 670 ( $\approx 20$ to $150 \mathrm{keV}$ )

d Expressed as the number of channels decreased. 


\section{DISCUSSION}

The differences in product yields of the chlorine separation experiments can be explained by the possible formation of manganese chloride compounds, such as $\mathrm{MnCl}_{2}, \mathrm{MnCl}_{3}, \mathrm{MnCl}_{4}, \mathrm{MnOCl}_{2}$, or $\mathrm{K}_{2} \mathrm{MnCl}_{5}$. Formation of these compounds consume chloride preventing formation of elemental chlorine. The experimental densities for 1,2-dichlorohexane confirm the formation of the desired product whose density is far from the density of 1-hexene.

In the iodine separations the only changes in the setup were performed on the nitrogen flow over the reaction mixture. To test the theory that hydrogen iodide was being lost, a closed reaction system was constructed. This closed system was similar to the original setup but placed a water trap after the overflow vial to prevent any atmospheric oxygen from backing up into the system. After all of the reactants were added to the flask the system was purged. The nitrogen gas line was removed and the outlet quickly capped off. This system provided a percent yield almost five times better than the initial open system. These results indicate the nitrogen purge over the water trap does not carry nearly as much hydrogen iodide out of the system as the purge which starts in the reaction flask, but it does carry out a significant amount. Overall results indicate the closed system to be the best method of iodine recovery, with the only significant problem being the possible recontamination of the system by oxygen after the nitrogen purge is disconnected.

The chlorine isolation procedure although workable may need to be improved through further research to increase product yield. The iodine isolation procedure works best when kept in a closed system. In all of the runs the density measurements indicated the presence of the correct product. 
Through these measurements it is known that the 1,2-dichlorohexane and 2iodohexane were prepared through the isolation processes, and that the experiment was successful in terms of isolating the desired organohalogen compound. Further research may be needed in the area of improving the product yield. The great quenching by 2 -iodohexane makes further work with it unacceptable.

Table 7 itemizes the types of wastes which would be generated during the course of a chlorine-36 determination using the techniques described here. Since chlorine-36 may be entrained in the manganese dioxide, further work regarding waste minimization options, i.e., evaluation of additional oxidation systems for converting chloride to chlorine, may be desirable.

\section{TABLE 7}

Wastes Generated by Chloride Process

Product

$\mathrm{MnO}_{2}$

$\mathrm{H}_{2} \mathrm{SO}_{4}-\mathrm{Mn}^{2+}$

$\mathrm{HSO}_{4}$
Type of Waste/Possible Disposal Route

Oxidizer: filter the solid waste.

Acid solution: Make basic, filter the solid waste, and neutralize the basic solution.

Alkali metal hydrogen sulfate solution: neutralize. 


\section{ACXNOWLEDGEMENTS}

Associated Western Universities (AWU), Environmental Management Career Opportunities for Minorities (EMCOM) program for financial support (WJW).

\section{REFERENCES}

1. A.E. Norris, H.W. Bentley, S. Cheng, P.W. Kubik, P. Sharma and H.E. Gove, ${ }^{36} \mathrm{Cl}$ Studies of Water Movements Deep within Unsaturated Tuffs", Archaeology, 1990 , pp. 455-460

2. B.R. Scanlon, P.W. Kubik, P. Sharma, B.C. Richter, H.E. Gove, "Bomb Chlorine-36 Analysis in the Characterization of Unsaturated Flow at a Proposed Radioactive Waste Disposal Facility", Archaeology, 1990, pp. 489-492.

3. D. P. Lide (Ed.). Handbook of Chemistry and Physics, 1992-1993 (73th Edition), CRC Press, Boca Raton, FL.

4. G.F. Knoll, Radiation Detection and Measurement, John Wiley \& Sons, New York: 1979. pp. 350-352.

5. Organic Syntheses, Volume 31. John Wiley \& Sons Inc. New York: 1951. pp. $66-67$.

6. G.D. Parkes (Ed.). Mellor's Modern Inorganic Chemistry, Volume II. Longmans, Green and Co Ltd. New York: 1951. pp. 495-499.

7. J.W. Mellor, A Comprehensive Treatice on Inorganic and Theoretical Chemistry, Volume II. Longmans, Green and Co Ltd. New York: 1946. pp. $25-38$.

8. Organic Syntheses, Volume 31. John Wiley \& Sons Inc. New York: 1951. pp. $31-32$.

9. R.B. Wagner, H.D. Zook. Synthetic Organic Chemistry, John Wiley \& Sons. New York: 1953. pp. 90. 
$\bullet$

$\cdot$

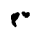

$\infty$

FIGURE 1. Chlorine Separation Schematic.

A. Reactant flask; B. Reflux condenser; $\mathrm{C}_{\text {. }} \mathrm{Cl}^{-}$addition funnel; D. Nitrogen purge inlet; Impinger Vials: \#1. Empty, \#2. $10 \mathrm{~mL}$ concentrated $\mathrm{H}_{2} \mathrm{SO}_{4}$, \#3. Primary hexene trap, \#4. Secondary hexene trap 


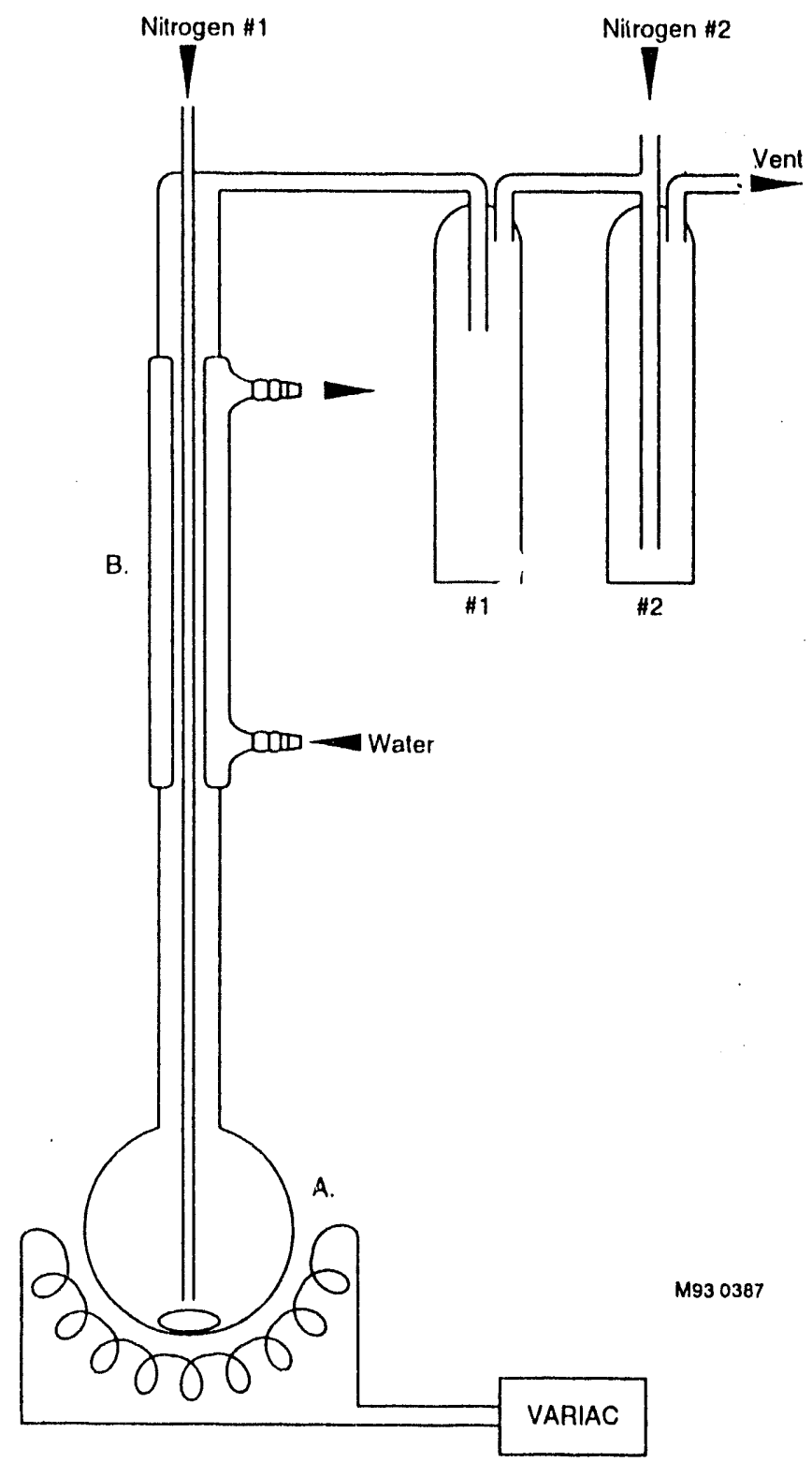

FIGURE 2. Iodine Separation Schematic.

A. Reactant flask; B. Reflux tube; C. Nitrogen purge inlet configuration:

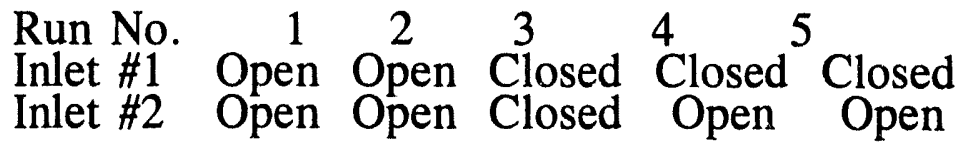

Impinger vials: \#1. Empty, \#2. Water seal. 

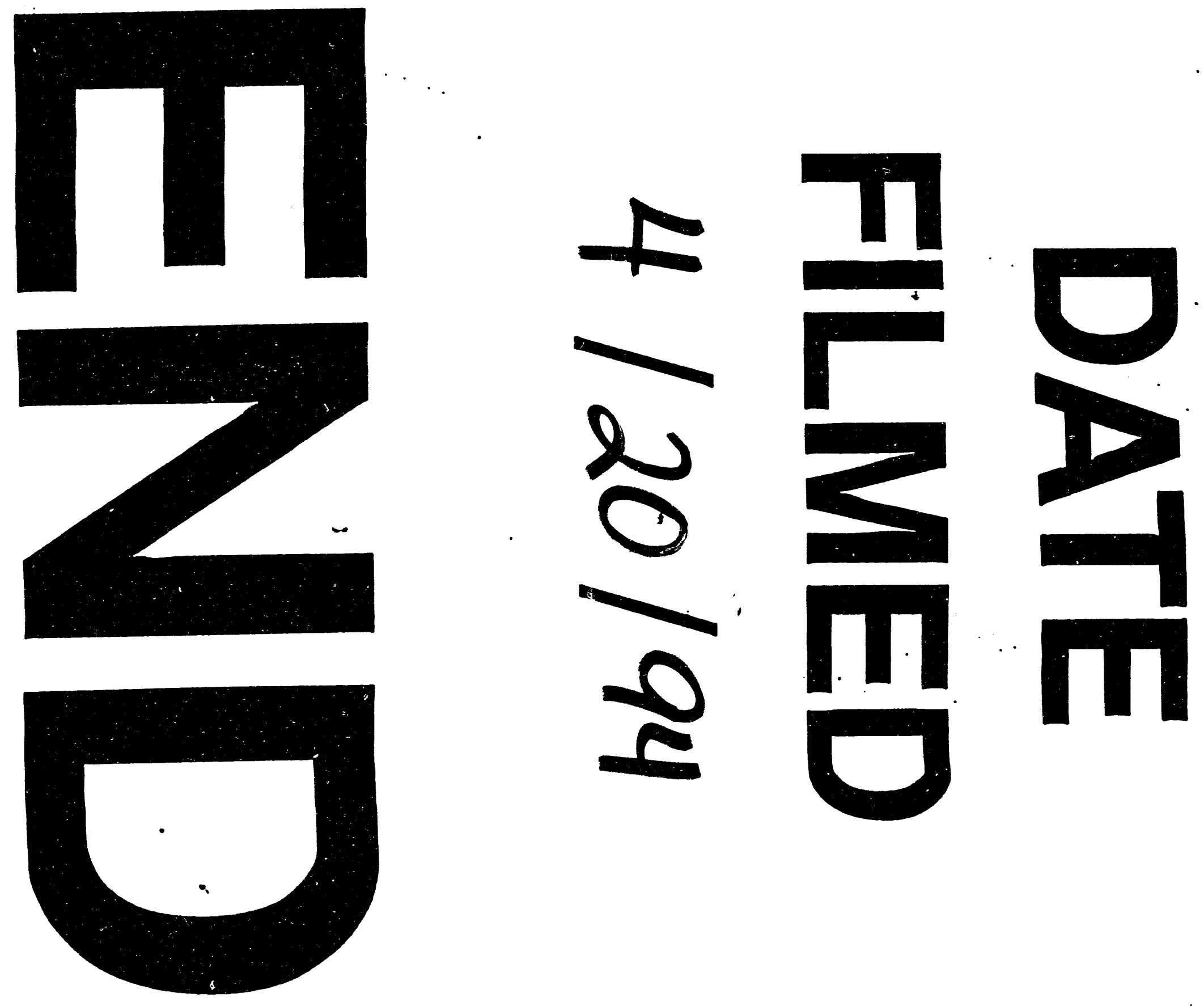
口. 